\title{
A Case of Recurrent Superficial Acral Fibromyxoma
}

\author{
Jawoong Goo, M.D., Ye-Jin Jung, M.D., Jae-Hong Kim, M.D., Sung-yul Lee, M.D., \\ Sung Ku Ahn, M.D., Ph.D.
}

Department of Dermatology, Wonju College of Medicine, Yonsei University, Wonju, Korea

Superficial acral fibromyxoma (SAFM) is a rare myxoid tumor that was first described in 2001. The presence of a very slow growing solitary tender mass in the subungual area is the typical clinical feature at presentation. Histopathologically, SAFM is composed of stellate cells in a myxocollagenous matrix with a poorly circumscribed margin. This tumor is thought to be benign, but its natural course is not fully understood. We describe a 15-year-old patient with recurrent SAFM and discuss the proper treatment and follow up. (Ann Dermatol 22(1) 110 113, 2010)

\section{-Keywords-}

Recurrent, Superficial acral fibromyxoma, Treatment

\section{INTRODUCTION}

Superficial acral fibromyxoma (SAFM) is a recently defined myxoid tumor with predilection for forming sub or periungual lesions ${ }^{1}$. This tumor usually presents as a slow growing tender mass in adult males. Histologically, it is a poorly circumscribed mass mainly composed of spindle or stellate neoplastic cells that show a variable degree of pleomorphism in a myxocollagenous stroma. The spindle cells have immunoreactivity for CD34, CD99, vimentin and focally for the epithelial membrane antigen. Blood vessels are predominant in the myxoid area and mast cells are scattered throughout the lesion. The natural course of SAFM is assumed to be benign from prior reports $^{1-7}$. We report a case of recurrent SAFM with follow up for two years.

Received June 1, 2009, Revised September 7, 2009, Accepted for publication September 28, 2009

Reprint request to: Sung Ku Ahn, M.D., Department of Dermatology, Wonju College of Medicine, Yonsei University, 162, Ilsan-dong, Wonju 220-701, Korea. Tel: 82-33-741-0621, Fax: 82-33-748-2650, E-mail: ahnsk@wonju.yonsei.ac.kr

\section{CASE REPORT}

A 15-year-old female presented with a slow growing lesion on the right index finger that formed three years previously. The patient reported that the nodule was tender and this made it hard to grasp a pen. The physical examination revealed that the nodule was mainly located in the subungual area and extended to the lateral nail fold where it disrupted the nail plate (Fig. 1). Illumination of the nodule with light showed no transparency, so it was not suspected to be a cystic lesion. Instead, the nodule was hard and fixed to the underlying tissue on palpitation. The plain x-ray radiograph was normal. The past medical and family history was noncontributory.

An incisional biopsy was performed after removal of the nail plate, under local anesthesia. Healing of the biopsy wound was planned by secondary intention due to its location. A nodule that was about $0.5 \mathrm{~cm}$ in size was incised from the lesion. The histopathological examination revealed that the tumor was located underneath the epidermis and was poorly circumscribed by the surrounding dermis (Fig. 2A). In the tumor, there was a collagen bundle that was filled with abundant myxoid material and stellate or fibroblast-like cells (Fig. 2B). These stellate cells with oval shaped plump nuclei and reticulated basophilic cytoplasm had a fascicular growth pattern that was observed by high power microscopy (Fig. 2C). Pleomorphism or mitotic figures were not noted. Few mast cells were found in the tumor. However, there was proliferation of the blood vessels accentuated in the highly mucinous area. Immunohistochemical staining revealed that the satellite cells were positive for CD34, epithelial membrane antigen (EMA) and vimentin, but negative for actin, desmin and S100. The results supported the diagnosis of a SAFM.

The patient was followed for two years. The biopsy site healed well. However, a recurrent tumor was noted 1 year 8 months after the initial procedure. The recurrent lesion 

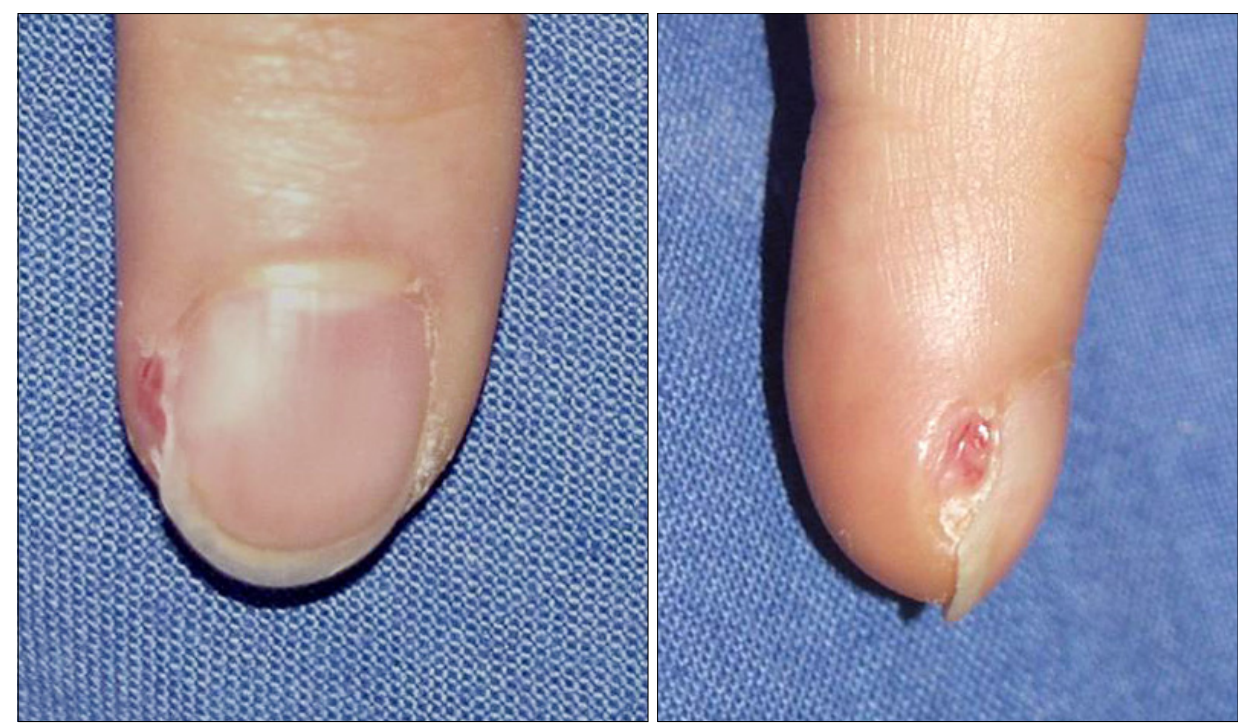

Fig. 1. The tender, growing subungual lesion and the distorted nail plate. The right side of the nail plate looked pale because of the pressing margin of the tumor.

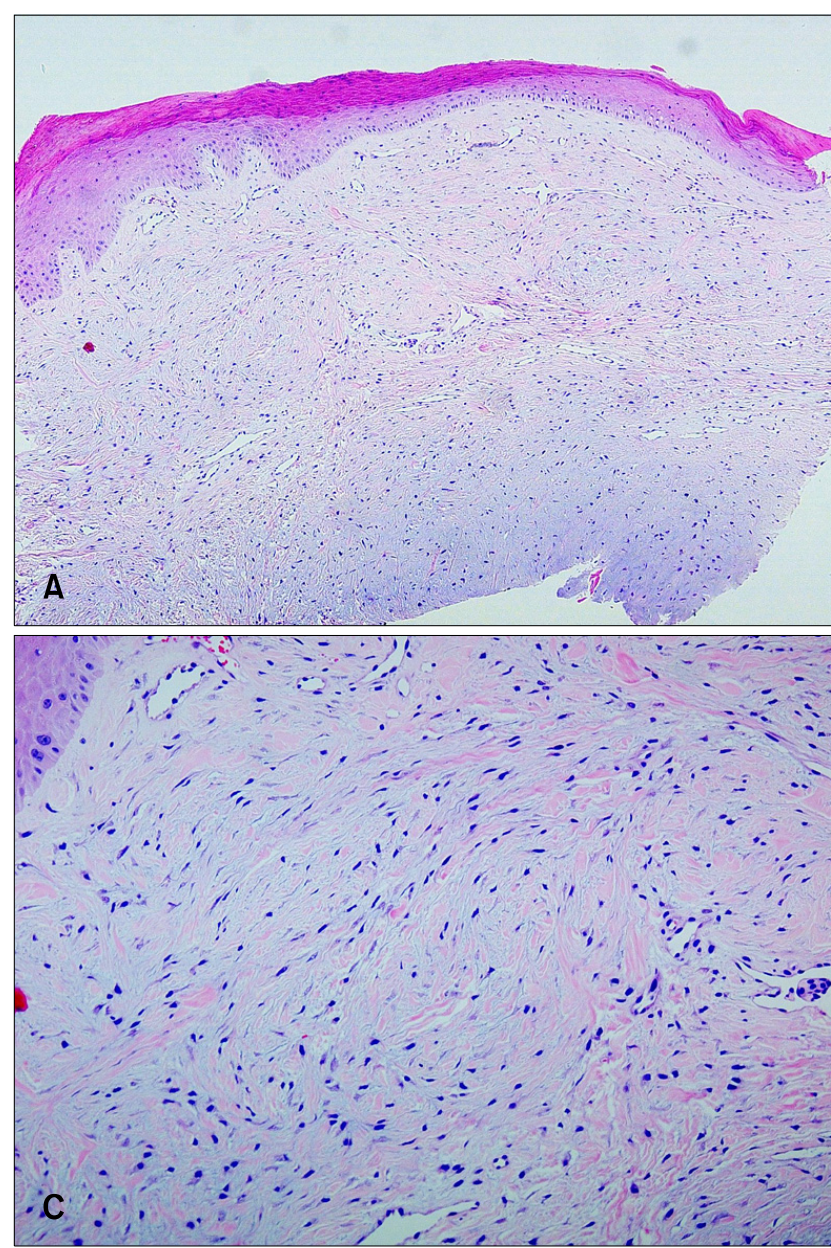

was slowly increasing in size, and the size at the two year follow up was similar to the first lesion (Fig. 3). We then planned to completely extirpate the lesion.

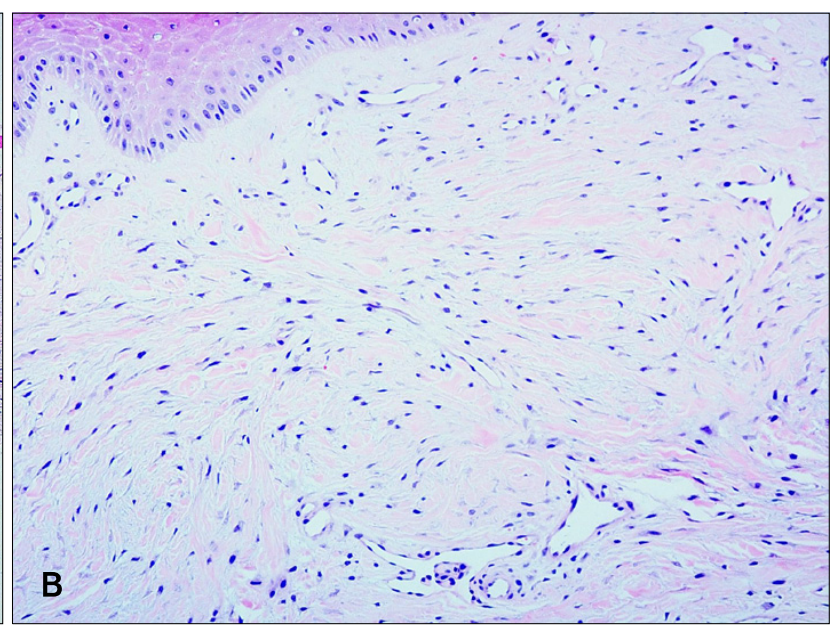

Fig. 2. (A) Poorly circumscribed dermal tumor with myxoid and fibrous areas $(H \& E, \times 40)$. (B) Stellate or fibroblast-like cells showing a fascicular growth pattern $(H \& E, \times 100)$. (C) Stellate cells with an elongated thin cytoplasm were noted in the collagenous and mucinous areas. Blood vessels proliferated focally. (H\&E, $\times 200)$.

\section{DISCUSSION}

Since Fetsch et al. ${ }^{1}$ first described a SAFM in 2001, additional cases have been reported. However, the natural 

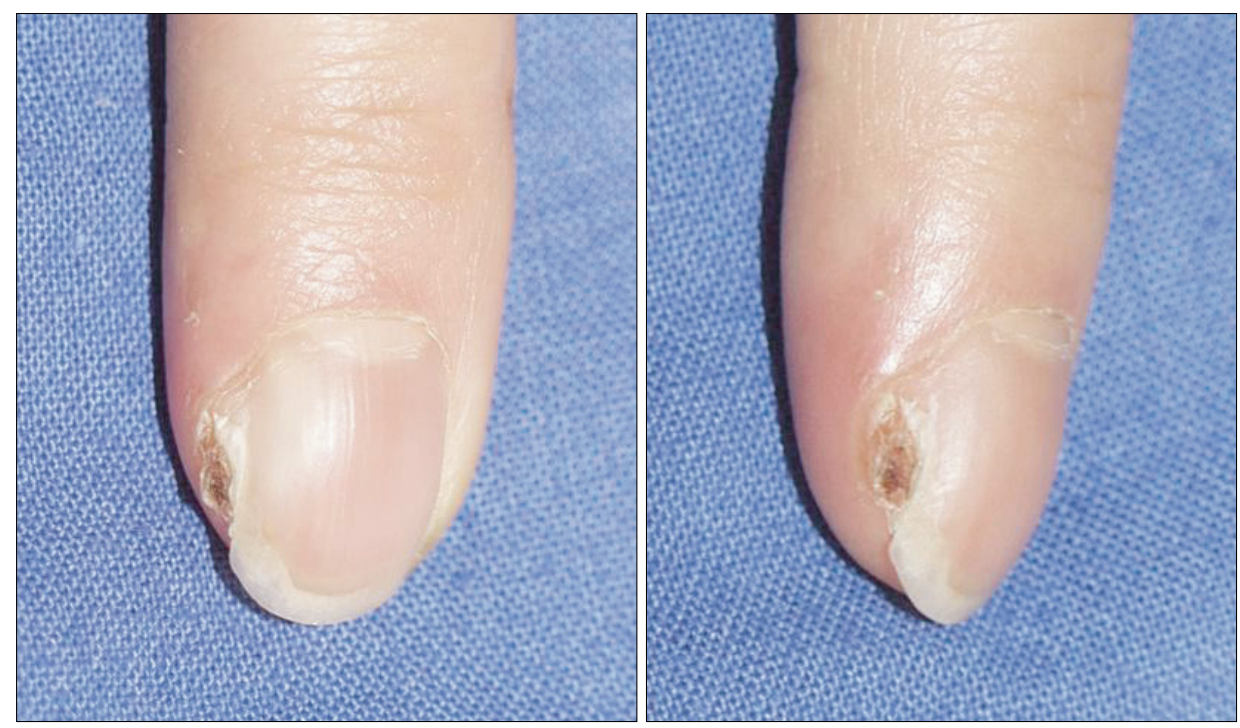

Fig. 3. A recurrent tumor was noted 1 year 8 months after the initial procedure.

Table 1. Summary of reported cases of superficial acral fibromyxoma

\begin{tabular}{|c|c|c|c|c|c|c|}
\hline Reference & No. of case & Patient & Site & $\begin{array}{c}\text { Duration } \\
\text { (year) }\end{array}$ & $\begin{array}{l}\text { Follow up } \\
\text { (year) }\end{array}$ & $\begin{array}{c}\text { Recurrence, } \\
\text { (year) }\end{array}$ \\
\hline \multirow[t]{2}{*}{1} & 25 & $43 / M$ & Toe (20) & $0.25 \sim 30$ & 10.9 &,$+(7)$ \\
\hline & 12 & $44 / F$ & Finger (13) & & & \\
\hline \multirow[t]{2}{*}{2} & 2 & $51 / M$ & Toe & ND & 0.7 & - \\
\hline & & $75 / F$ & Toe & & & \\
\hline 3 & 1 & $50 / F$ & 1st toe & 10 & ND & ND \\
\hline 4 & 1 & $53 / \mathrm{M}$ & 2nd finger & 6 & 0.5 & - \\
\hline 5 & 1 & $71 / \mathrm{M}$ & 4th finger & 10 & ND & ND \\
\hline 6 & 1 & $71 / M$ & 1st finger & 2 & ND & ND \\
\hline 7 & 1 & $35 / M$ & Toe & 2 & 2 & - \\
\hline This case & 1 & $15 / F$ & 2nd finger & 3 & 2 &,$+(1.67)$ \\
\hline
\end{tabular}

ND: not described.

course of this lesion is not fully known ${ }^{2-7}$. SAFMs arise in the nail region and are commonly found on the toes of adult males. Onset in younger patients is not common according to the medical literature. Preceding trauma has been noted in a minority of the cases. The mass usually is tender and can have a long duration of up to 30 years before presentation. The tenderness varies and is not severe in all cases ${ }^{1}$. Rarely this lesion also occurs on the ventral surface of a finger or toe $e^{1,5}$. The reported cases are summarized in Table 1.

Histopathologically, this distinctive tumor is composed of stellate shaped and spindled fibroblast-like tumor cells in a variable degree of admixed myxoid or collagenous matrices. As the tumor persists, the collagenous matrix has a tendency to become predominant over the myxoid matrix ${ }^{1}$. The stellate cells show a loose storiform, and a fascicular or random growth pattern. Mild nuclear atypia or pleomorphism of the stellate cells is present, but atypical mitotic figures are absent. Typically the satellite cells are positive for CD34, CD99, vimentin and focally for EMA; however, the results of the EMA are not a consistent finding ${ }^{2-7}$. The proliferation of blood vessels is noted in the myxoid area and the mast cells are easily identified. The margin of the tumor is not circumscribed, but grossly shows a lobular pushing or infiltrative margin. Tumor involvement of the periosteal region has been described $^{1,3,6}$.

The differential diagnosis for an acral soft tissue tumor includes myxoid dermatofibrosarcomas protuberans, myxoid neurofibromas, myxoid fibrous histiocytomas, low grade myxofibrosarcomas and acquired digital fibrokeratomas. Myxoid dermatofibrosarcomas protuberans are rare, but the histological features are similar. CD34 positive uniform spindle cells with a focally tight storiform in a less mucinous area that infiltrates the subcutis are characteristics of a myxoid dermatofibrosarcoma protuberans. A 
negative result on EMA testing is helpful for the differentiation from SAFMs. In the case of incomplete excision, local recurrence is likely, as is a malignant neoplasm ${ }^{1,8}$. In myxoid neurofibromas, the immunoreactivity to $\mathrm{S} 100$ as a marker for neural origin and the lack of vasculature in the tumor mass distinguish them from SAFMs ${ }^{9}$. Myxoid fibrous histiocytomas contain spindle cells in the storiform as well as sclerotic collagen at the periphery of the lesion. The myxoid area is not as abundant as it is in SAFMs, and it has positive immunoreactivity for factor XIIla antigen, but not for CD34 ${ }^{10}$. Low grade myxofibrosarcomas contain small stellate cells with pleomorphic nuclei around the blood vessels and pseudolipoblasts ${ }^{9}$. Acquired digital fibrokeratomas are mainly composed of paucicellular vertically interwoven collagen bundles with a collarlette $e^{1,3}$.

The natural course of SAFM appears to be benign. However, the histopathological spectrum of stellate tumor cells ranges from mild to pronounced nuclear atypia with mitotic figures. Therefore, transformation of a SAFM to a low grade malignant tumor is possible ${ }^{1}$. Clinically, local recurrence without evidence of distant metastasis was noted only in one patient among the reported cases ${ }^{1}$. Thus, complete excision with adequate margins is mandatory. Furthermore, follow up is necessary because of its slow growing nature and possible recurrence.

In conclusion, SAFMs are rare neoplasms that have been recently defined. The possibility of a SAFM should be considered when a patient presents with a slow growing tender periungual mass. Regarding the treatment, excision of the mass is necessary, but the mass may recur and therefore follow up is needed. This case illustrates the recurrence of a SAFM and the need for long-term follow up.

\section{REFERENCES}

1. Fetsch JF, Laskin WB, Miettinen M. Superficial acral fibromyxoma: a clinicopathologic and immunohistochemical analysis of 37 cases of a distinctive soft tissue tumor with a predilection for the fingers and toes. Hum Pathol 2001;32:704-714.

2. Kazakov DV, Mentzel T, Burg G, Kempf W. Superficial acral fibromyxoma: report of two cases. Dermatology 2002;205: 285-288.

3. Andre J, Theunis A, Richert B, de Saint-Aubain N. Superficial acral fibromyxoma: clinical and pathological features. Am J Dermatopathol 2004;26:472-474.

4. Meyerle JH, Keller RA, Krivda SJ. Superficial acral fibromyxoma of the index finger. J Am Acad Dermatol 2004;50: 134-136.

5. Quaba O, Evans A, Al-Nafussi AA, Nassan A. Superficial acral fibromyxoma. Br J Plast Surg 2005;58:561-564.

6. Abou-Nukta F, Fiedler P, Parkash V, Arons J. Superficial acral fibromyxoma of the distal phalanx of the thumb. J Hand Surg Br 2006;31:619-620.

7. Oteo-Alvaro A, Meizoso T, Scarpellini A, Ballestin C, Perez-Espejo G. Superficial acral fibromyxoma of the toe, with erosion of the distal phalanx. A clinical report. Arch Orthop Trauma Surg 2008; 128:271-274.

8. Frierson HF, Cooper PH. Myxoid variant of dermatofibrosarcoma protuberans. Am J Surg Pathol 1983;7:445-450.

9. Graadt van Roggen JF, Hogendoorn PC, Fletcher CD. Myxoid tumours of soft tissue. Histopathology 1999;35: 291-312.

10. Zelger BG, Calonje E, Zelger B. Myxoid dermatofibroma. Histopathology 1999;34:357-364. 